\title{
Quantitative trait loci on chromosome 5 for susceptibility to frequency-specific effects on hearing in DBA/2J mice
}

\author{
Sari SUZUKI ${ }^{1,2)}$, Masashi ISHIKAWA ${ }^{2)}$, Takuya UEDA ${ }^{2)}$, Yasuhiro OHSHIBA ${ }^{1,3)}$, \\ Yuki MIYASAKA ${ }^{1,3)}$, Kazuhiro OKUMURA ${ }^{1,4)}$, Michinari YOKOHAMA ${ }^{2}$, Choji TAYA $^{5)}$, \\ Kunie MATSUOKA ${ }^{1}$, and Yoshiaki KIKKAWA ${ }^{1,3)}$ \\ 1) Mammalian Genetics Project, Department of Genome Medicine, Tokyo Metropolitan Institute of Medical Science, \\ 2-1-6 Kamikitazawa, Setagaya-ku, Tokyo 156-8506, Japan \\ ${ }^{2)}$ Department of Bioproduction, Tokyo University of Agriculture, 196 Yasaka, Abashiri, Hokkaido 099-2493, Japan \\ ${ }^{3)}$ Graduate School of Medical and Dental Sciences, Niigata University, 1-757 Asahimachi, Niigata 951-8510, \\ Japan \\ 4) Laboratory of Experimental Animals, Chiba Cancer Center Research Institute, 666-2 Nitona-cho, Chuo-ku, Chiba \\ 260-8717, Japan \\ ${ }^{5)}$ Laboratory for Transgenic Technology, Tokyo Metropolitan Institute of Medical Science, 2-1-6 Kamikitazawa, \\ Setagaya-ku, Tokyo 156-8506, Japan
}

\begin{abstract}
The DBA/2J strain is a model for early-onset, progressive hearing loss in humans, as confirmed in the present study. DBA/2J mice showed progression of hearing loss to low-frequency sounds from ultrasonic-frequency sounds and profound hearing loss at all frequencies before 7 months of age. It is known that the early-onset hearing loss of DBA/2J mice is caused by affects in the $a h l\left(C d h 23^{a h l}\right)$ and ahl8 $\left(F s c n 2^{\text {ahl }}\right)$ alleles of the cadherin 23 and fascin 2 genes, respectively. Although the strong contributions of the Fscn2 ${ }^{\text {ahl }}$ allele were detected in hearing loss at 8- and 16$\mathrm{kHz}$ stimuli with LOD scores of 5.02 at $8 \mathrm{kHz}$ and 8.84 at $16 \mathrm{kHz}$, hearing loss effects were also demonstrated for three new quantitative trait loci (QTLs) for the intervals of 50.3-54.5, 64.6-119.9, and 119.9-137.0 Mb, respectively, on chromosome 5, with significant LOD scores of 2.80-3.91 for specific high-frequency hearing loss at $16 \mathrm{kHz}$ by quantitative trait loci linkage mapping using a $(\mathrm{DBA} / 2 \mathrm{~J} \times \mathrm{C} 57 \mathrm{BL} / 6 \mathrm{~J}) \mathrm{F}_{1} \times \mathrm{DBA} / 2 \mathrm{~J}$ backcross mice. Moreover, we showed that the contribution of Fscn2 $2^{\text {ahl8 }}$ to early-onset hearing loss with $32-\mathrm{kHz}$ stimuli is extremely low and raised the possibility of effects from the Cdh23 $3^{\text {ahl }}$ allele and another dominant quantitative trait locus (loci) for hearing loss at this ultrasonic frequency. Therefore, our results suggested that frequency-specific QTLs control early-onset hearing loss in DBA/2J mice.
\end{abstract}

Key words: ahl locus, chromosome 5, DBA/2J, early-onset hearing loss, quantitative trait loci (QTL)

\section{Introduction}

Hearing loss is the most common sensory disease in the human population and severely affects the quality of life. Although the causes of hearing loss are diverse, involving both genetic and environmental factors, half of hearing loss cases are considered to have a genetic origin [23]. Indeed, many genetic loci responsible for

(Received 24 December 2014 / Accepted 8 January 2015 / Published online in J-STAGE 10 March 2015)

Address corresponding: Y. Kikkawa, Mammalian Genetics Project, Tokyo Metropolitan Institute of Medical Science, 2-1-6 Kamikitazawa,

Setagaya-ku, Tokyo 156-8506, Japan

Supplementary tables and figures: refer to J-STAGE: https://www.jstage.jst.go.jp/browse/expanim

(C)2015 Japanese Association for Laboratory Animal Science 
hearing loss have been mapped in humans by linkage analyses [Hereditary Hearing Loss Homepage: http:// hereditaryhearingloss.org/]. Moreover, many mutations responsible for hearing loss have been recently identified in humans. Most of these mutations are primarily associated with congenital hearing loss caused by a single gene; however, little information exists concerning acquired hearing loss such as progressive hearing loss (PHL), age-related hearing loss (AHL), and presbyacusis.

Acquired hearing loss is a complex disease and occurs through the effects of several quantitative trait loci (QTLs) and environmental risk factors, such as exposure to noise, aging, ototoxic drugs, and viral and bacterial infections, which are major causes of hearing loss [6,21]. The effects of environmental risk factors pose a particular challenge to genetic analysis because understanding all of the negative effects of hearing caused by environmental factors throughout a patient's life is impossible. Therefore, the association of QTLs with acquired hearing loss is only defined at a chromosomal locus [7], although there are several challenges associated with genomewide association studies (GWASs) [e.g., 5, 8, 34, 37].

To identify QTLs associated with acquired hearing loss, inbred strains of mice offer important advantages as bioresources because of the controlled handling environment, ability to maintain genetic stability [3], wellcharacterized genetic polymorphisms [16,33], and hearing abilities among the strains $[19,38]$. Within the inbred strains, several strains have been characterized as models of acquired hearing loss through measurements of hearing $[13,19,38]$. Moreover, previous studies have reported that the inbred strains exhibit variable hearing ability and onset times of hearing loss [13, 38]. For example, the C57BL/6J (B6J) strain is a well-known mouse model of late-onset AHL and develops severe hearing loss with respect to stimuli at mid frequencies $(1-10 \mathrm{kHz})$ at 9-15 months of age, stimuli at high frequencies (10$20 \mathrm{kHz}$ ) at $4-10$ months of age, and stimuli at ultrasonic frequencies $(<20 \mathrm{kHz})$ at $2-6$ months of age $[10,22]$. By contrast, the DBA/2J (D2J) strain shows early-onset AHL (PHL). The hearing loss of D2J mice rapidly progresses to the low frequencies from the ultrasonic frequencies and to profound levels at approximately 8 months of age [15].

Previous studies have confirmed that the ahl mutation $\left(C d h 23^{a h l}\right.$, c. $\left.753 \mathrm{G}>\mathrm{A}\right)$ of cadherin 23 (Cdh23) is responsible for AHL in multiple inbred mouse strains [26].
Although both the B6J and D2J strains have a homozygous allele of $C d h 23^{\text {ahllahl }}$, AHL occurs significantly much earlier in D2J than B6J. This difference in AHL onset time is suggested to contribute to other genetic factors in addition to the $C d h 23^{a h l}$ allele in D2J mice. Johnson et al. [15] found that the early-onset AHL of D2J mice was significantly associated with a locus on chromosome 11, designated ahl8. Moreover, Shin et al. [31] confirmed that the responsible mutation of ahl8 is the c.326G $>$ A missense mutation (p.Arg109His) in the fascin 2 gene ( $F s c n 2)$, which encodes an actin crosslinking protein. In addition, Nagtegaal et al. [25] reported that the ahl9 locus on chromosome 18 is tightly linked to early-onset and low-frequency-specific AHL in D2J mice. Thus, these studies suggest that the onset of AHL is accelerated by the effects of several susceptibility QTLs.

In this study, we reported that the hearing loss in D2J mice is more severe with high-frequency $(16 \mathrm{kHz})$ and ultrasonic-frequency $(32 \mathrm{kHz})$ stimuli than with midfrequency $(8 \mathrm{kHz})$ stimuli. Moreover, we also report that the early-onset AHL in D2J mice is associated with QTLs on chromosome 5 that only show high-frequency-specific effects on hearing loss.

\section{Materials and Methods}

\section{Mice and ethics statement}

The DBA/2JJcl (D2J) and C57BL/6JJcl (B6J) strains were purchased from Clea Japan (Tokyo, Japan) and were maintained at the animal facility at the Tokyo Metropolitan Institute of Medical Science and the Tokyo University of Agriculture. All of the procedures involving animals met the guidelines described in the Proper Conduct of Animal Experiments, as defined by the Science Council of Japan, and were approved by the Animal Care and Use Committee on Ethics of the Tokyo Metropolitan Institute of Medical Science and the Tokyo University of Agriculture.

\section{Measurements of the auditory brain stem response}

An auditory brain stem response (ABR) workstation (TDT System III, TDT, Alachua, FL, USA) was used to test mice for $\mathrm{ABR}$ thresholds as previously described [22]. The ABR thresholds from both ears in all of the mice were measured using a tone pip stimulus at 8,16 , and $32 \mathrm{kHz}$. 


\section{Linkage quantitative trait locus analyses}

Genetic mapping of the susceptibility loci in D2J mice linked to early-onset AHL was performed using (D2J $\times$ B6J) $F_{1}\left(B_{1} F_{1}\right) \times D 2 J$ backcross progeny $\left(N_{2}\right)$. DNA samples from $90 \mathrm{~N}_{2}$ mice were genotyped using 103 polymorphic microsatellite markers located throughout the mouse genome (Supplementary Table 1), which were selected from the Microsatellite Data Base of Japan (http://www.shigen.nig.ac.jp/mouse/mmdbj/top.jsp) based on size variation between PCR products from D2J and B6J mice. PCR amplification was carried out using a KAPA2G Fast PCR Kit (Kapa Biosystems, Woburn, MA, USA), and the cycle conditions were as follows: 1 cycle at $95^{\circ} \mathrm{C}$ for $2 \mathrm{~min}$ and 40 cycles at $95^{\circ} \mathrm{C}$ for $15 \mathrm{~s}$, $58^{\circ} \mathrm{C}$ for $20 \mathrm{~s}$, and $72^{\circ} \mathrm{C}$ for $5 \mathrm{~s}$. The PCR products were then subjected to $4 \%$ agarose gel electrophoresis. ABR thresholds at 8,16 , and $32 \mathrm{kHz}$ at 3 months of age ( \pm 5 days) were evaluated as quantitative traits for genetic mapping in the $\mathrm{N}_{2}$ mice. The linkage mapping was performed by QTL interval mapping using the R/qtl program of the R Statistical package to perform singleQTL genome scans by Haley-Knott regression using a step size of $1.0 \mathrm{cM}$ [2]. The logarithm of odds (LOD) scores for significance were calculated by 1,000 permutations testing using R/qtl. Additional statistical comparisons were evaluated using the Student's $t$-test with Welch's correction for the differences between two groups and one-way ANOVA with Tukey's post hoc multiple comparison test for differences among multiple groups. GraphPad Prism 5 (GraphPad Software, San Diego, CA, USA) was used to calculate column statistics and compute $P$ values. All of the results are presented as the mean \pm standard deviation (SD).

\section{Mutation screening}

Mutation analysis was performed on cDNA synthesized as previously described [22] from cochleae at 3 weeks of age and brain stems at 12 weeks of age in D2J and B6J mice using primers (Supplementary Table 2) designed to amplify and sequence the coding exons and partial UTRs of the urocortin (Ucn), glutaredoxin, cysteine rich 1 (Grxcr 1), purinergic receptor P2X, ligand-gated ion channel, 2 (P2rx2), Sad1 and UNC84 domain containing 1 (Sun1), Fascin 1 (Fscn1), and actin, beta $(A c t b)$, genes. For partial sequencing of $P 2 r x 2$ and Sun1, we used genomic DNA to screen the mutations because we failed to sequence the 3 ' region of their $\mathrm{cD}$ NAs for alternative splicing. Amplification was carried out at $94^{\circ} \mathrm{C}$ for $2 \mathrm{~min}$ followed by 45 cycles of $98^{\circ} \mathrm{C}$ for $10 \mathrm{~s}$ and $68^{\circ} \mathrm{C}$ for $3 \mathrm{~min}$ using KOD-FX Neo (Toyobo, Osaka, Japan). The products were purified using a QIAquick Gel Extraction Kit (Qiagen, Valencia, CA, USA), sequenced using a BigDye Terminator Kit (Life Technologies, Grand Island, NY, USA), and analyzed using an Applied Biosystems 3130xl Genetic Analyzer.

\section{Quantitative RT-PCR}

The cDNAs from the cochleae in D2J and B6J mice at 3 weeks were used for quantitative RT-PCR (qRTPCR). Grxcr1, P2rx2, Sun1, Fscn1, and Actb were amplified and quantified using a QuantiTect SYBR Green PCR Kit (Qiagen, Valencia, CA, USA) and LightCycler 480 Instrument (Roche Diagnostics, Tokyo, Japan), respectively, according to the manufacturer's protocol. The primers used for the detection of these transcripts are shown in Supplementary Table 3. The signal values were normalized to the hypoxanthine-guanine phosphoribosyl transferase (Hprt) median signals, and the geometric means of target signals were calculated in triplicate. The gene expression levels were compared between the D2J and B6J mice using the Student's $t$-test with Welch's correction.

\section{Results}

\section{Hearing assessment of D2J mice}

Although data for ABR thresholds in DBA/2J mice have been reported by several research groups, there are moderate differences $[13,15,25,31,38]$. To evaluate hearing abilities, we measured the ABR to tone-pip stimuli at 8,16 , and $32 \mathrm{kHz}$ in mice from a D2J strain. Figure 1 shows the representative ABR waveforms with 8-, 16-, and 32-kHz stimuli recorded from B6J and D2J mice at 2 months of age. In the waveforms from B6J mice, the latency peak responses for peaks $\mathrm{I}-\mathrm{V}$ were detected at all frequencies, but the peak response was decreased at $32 \mathrm{kHz}$. By contrast, the waveforms from D2J mice lack peak $\mathrm{V}$ and obviously showed decreased peak responses at all frequencies compared with those of B6J mice (Fig. 1). We next determined the ABR thresholds for tone-pip stimuli at 8,16 , and $32 \mathrm{kHz}$ in D2J mice at 1-12 months of age at 1-month intervals compared with our previous data for B6J mice [22]. At 1 month of age, the ABR thresholds of the D2J mice were significantly higher than those of B6J mice for all frequency stimuli, and the mice exhibited levels of se- 


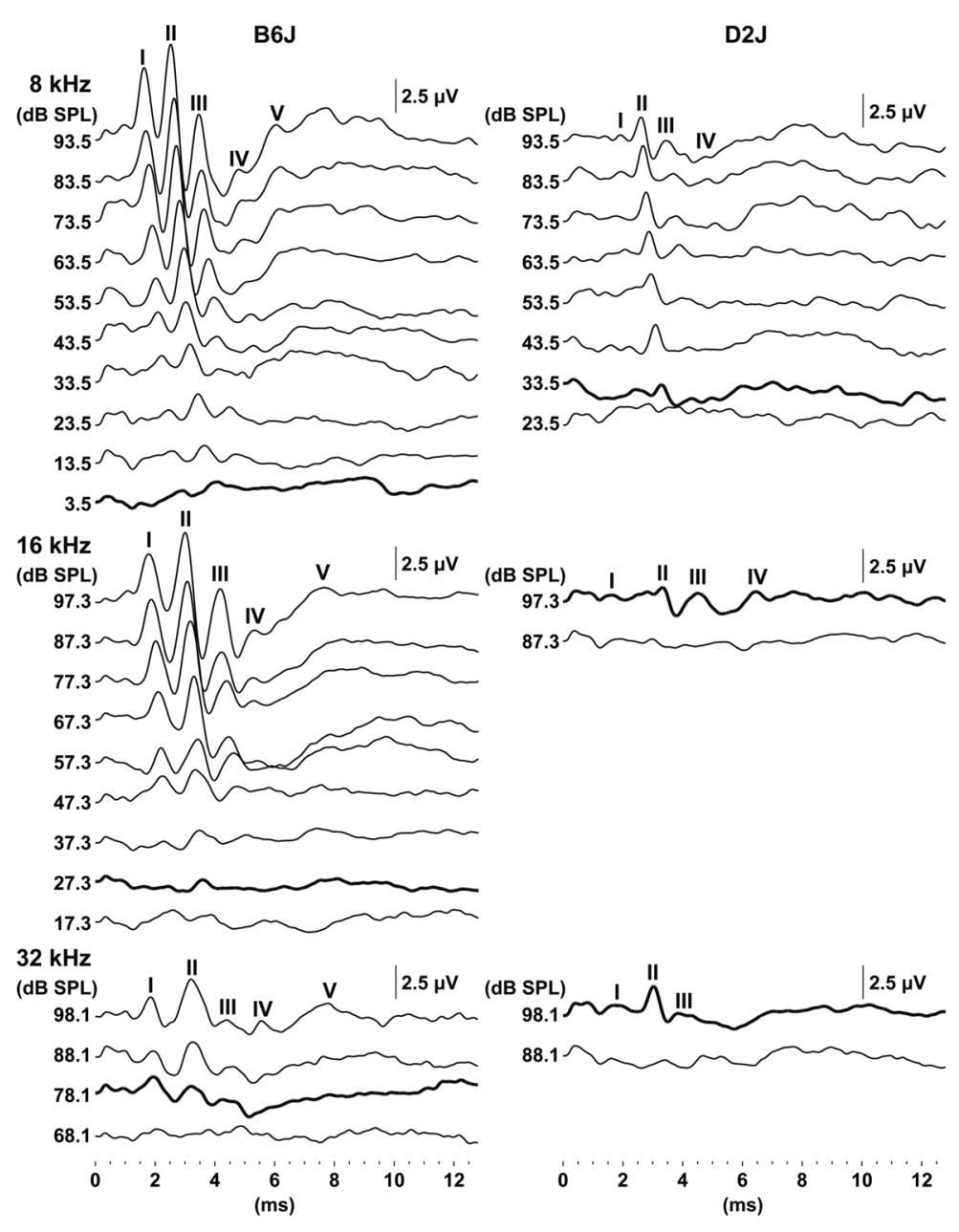

Fig. 1. Representative ABR waveforms with 8-, 16-, and 32-kHz stimuli recorded from B6J and D2J mice at 2 months of age. The waveforms represent the $\mathrm{ABR}$ in response to the intensities of tone-pip stimuli decreasing from 93.5 to $3.5 \mathrm{~dB}$ SPL at $8 \mathrm{kHz}$, from 97.3 to $17.3 \mathrm{~dB}$ SPL at $16 \mathrm{kHz}$, and from 98.1 to $68.1 \mathrm{~dB}$ SPL at $32 \mathrm{kHz}$. Bold lines represent the detected thresholds. The locations of peaks I-V are indicated.

vere (71-90 dB SPL) and profound ( $<91 \mathrm{~dB}$ SPL) hearing loss at 16 and $32 \mathrm{kHz}$, respectively (Fig. 2 and Supplementary Table 4). The hearing loss of the D2J mice rapidly progressed to the low frequencies from the high frequencies and to profound levels at the mean thresholds for 8-kHz stimuli at 7 months of age and 16$\mathrm{kHz}$ stimuli at 3 months of age (Fig. 2 and Supplementary Table 4). Although the ABR thresholds in D2J mice were slightly high compared with those in previous reports, the patterns of hearing degeneration were similar to those in most reports $[13,15,31,38]$.
Genetic analyses for early-onset AHL in D2J mice

Previous studies have reported that high-frequency and low-frequency early-onset AHL are linked to the ahl8 locus [15] on chromosome 11 and to the ahl9 locus [25] on chromosome 18. To confirm the genetic effects in early-onset AHL in D2J mice, we produced $\mathrm{F}_{1}$ and backcross $\mathrm{N}_{2}$ progeny by crossing with $\mathrm{B} 6 \mathrm{~J}$ mice and measured the ABR thresholds for 8-, 16-, and 32-kHz stimuli at 3 months of age. The mean ABR thresholds at 8 and $16 \mathrm{kHz}$ in $\mathrm{BDF}_{1}$ mice were $16.8 \pm 10.1 \mathrm{~dB}$ SPL and $21.4 \pm 6.3 \mathrm{~dB}$ SPL, respectively, and were not significantly different compared with the thresholds (22.9 $\pm 4.7 \mathrm{~dB}$ SPL at $8 \mathrm{kHz}$ and $27.4 \pm 6.9 \mathrm{~dB}$ SPL at $16 \mathrm{kHz}$ ) 

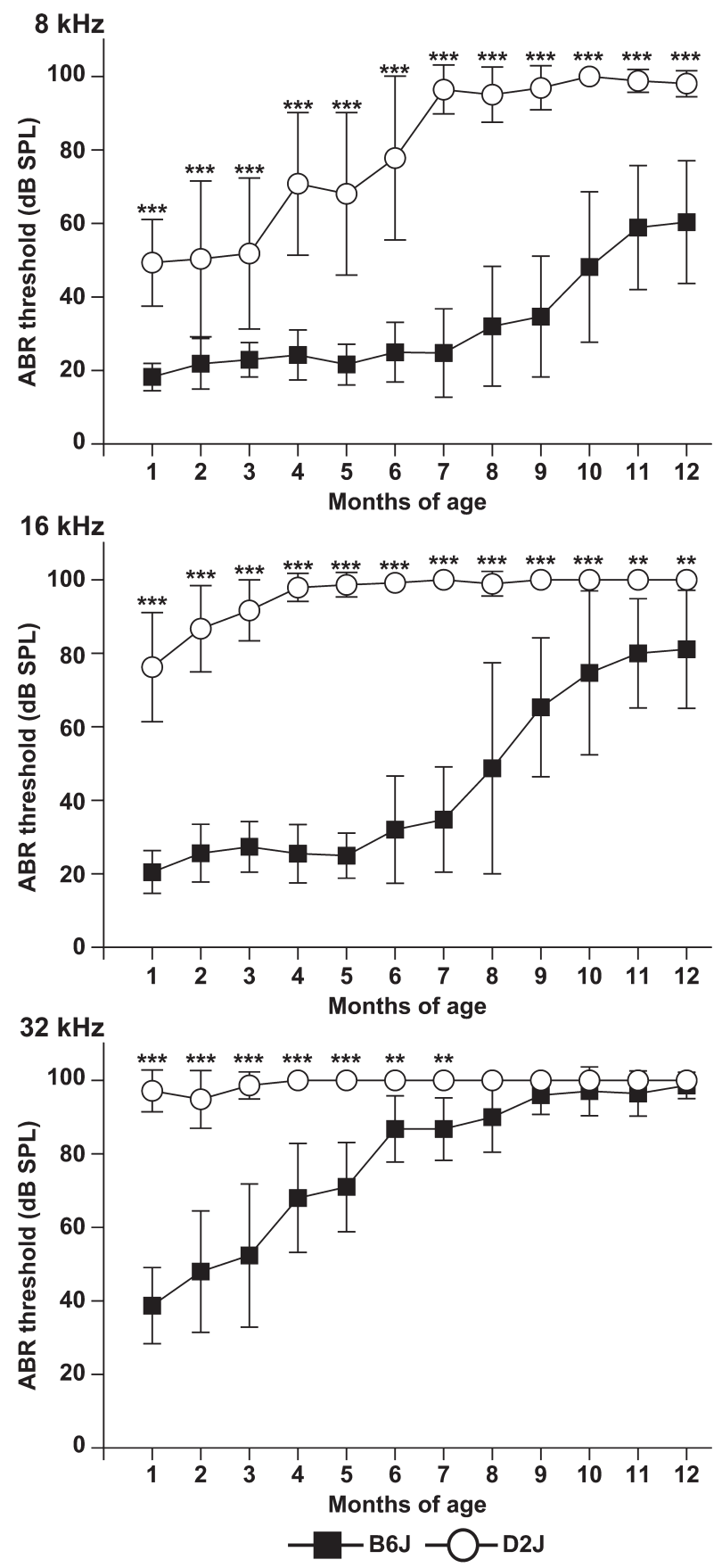

Fig. 2. Early-onset progressive hearing loss in D2J mice. The means (black squares in B6J and white circles in D2J) and SDs (error bars) of ABR threshold measurements for 8-, 16-, and $32-\mathrm{kHz}$ stimuli are shown for each mouse strain at 1 to 12 months of age. The number of ears tested is listed in Supplementary Table 4. ${ }^{* *} P<0.01 ; * * * P<0.001$.

[22] of B6J mice (Fig. 3A and Supplementary Table 4). The ABR thresholds at 8 and $16 \mathrm{kHz}$ in $\left(\mathrm{BDF}_{1} \times \mathrm{D} 2 \mathrm{~J}\right)$ $\mathrm{N}_{2}$ mice were $31.9 \pm 20.5$ and $62.1 \pm 25.7 \mathrm{~dB}$ SPL, re- spectively, which were slightly higher than those of B6J mice (Supplementary Table 4). Although the distribution of ABR thresholds for $8-\mathrm{kHz}$ stimuli in the $\left(\mathrm{BDF}_{1} \times \mathrm{D} 2 \mathrm{~J}\right)$ $\mathrm{N}_{2}$ mice barely followed a normal distribution $\left(R^{2}=\right.$ 0.7525 ), the thresholds of the $\mathrm{N}_{2}$ population were widely distributed from high to low levels (Fig. 3B). By contrast, the mean $\mathrm{ABR}$ thresholds at $32 \mathrm{kHz}$ in the $\mathrm{BDF}_{1}$ and $\left(\mathrm{BDF}_{1} \times \mathrm{D} 2 \mathrm{~J}\right) \mathrm{N}_{2}$ mice were $91.4 \pm 7.4$ and $94.0 \pm$ $7.8 \mathrm{~dB}$ SPL, respectively, and were similar to the threshold $(98.6 \pm 3.7)$ detected in D2J mice (Fig. 3A and Supplementary Table 4). These data for the ABR thresholds from the $F_{1}$ and $N_{2}$ populations suggested that the QTLs responsible for hearing loss in D2J mice differed according to the sound frequency.

To define the susceptibility locus underlying hearing loss in D2J mice, we performed genome-wide QTL linkage mapping based on the ABR thresholds with 8- and 16-kHz stimuli, which showed a normal distribution. QTL linkage analysis of the $\left(\mathrm{BDF}_{1} \times \mathrm{D} 2 \mathrm{~J}\right) \mathrm{N}_{2}$ progeny revealed a strong QTL on chromosome 11 with significant LOD scores of 5.02 at $8 \mathrm{kHz}$ and 8.84 at $16 \mathrm{kHz}$ (Fig. 4A and Table 1). The locus (marker D11Mit103) was in the same position as ahls, indicating a strong effect of the homozygous Fscn $2^{\text {ahl }}$ allele on hearing loss in D2J mice. Although we could not detect the other QTL with significant LOD scores at $8 \mathrm{kHz}$, including the $a h l 9$ locus on chromosome 18, QTL peaks were revealed on chromosome 5 with significant LOD scores of 2.80-3.91 at 12 markers located approximately within the 52.7126.1 $\mathrm{Mb}$ region by analysis using ABR thresholds at $16 \mathrm{kHz}$ (Fig. 4B and Table 1). The peak LOD score of 3.91 on chromosome 5 was detected at marker D5Mit233 (52.7 Mb; Fig. 4B and Table 1). Subsequently, the second and third peak LOD scores of 3.89 and 3.78 were detected at markers D5Mit214 (126.1 Mb) and D5Mit7 $(93.3 \mathrm{Mb})$, respectively, suggesting that there are multiple QTLs on chromosome 5 that contribute to hearing loss at $16 \mathrm{kHz}$ in D2J mice (Fig. 4B and Table 1).

Next, we analyzed the associations between phenotypes and genotypes in $\left(\mathrm{BDF}_{1} \times \mathrm{D} 2 \mathrm{~J}\right) \mathrm{N}_{2}$ mice to confirm the effects of the Fscn $2^{\text {ahls }}$ and QTLs on chromosome 5 because it is possible that the QTLs on chromosome 5 are false positives due to the limited sample size and distribution across a wide range on chromosome 5 (Fig. 4 and Table 1). First, we reconfirmed this analysis using D11Mit 103 to mark the Fscn $2^{\text {ahl }}$ locus and evaluated its effect on hearing loss at $16 \mathrm{kHz}$ in $\mathrm{N}_{2}$ mice. Most $\mathrm{N}_{2}$ mice exhibited elevated ABR thresholds from the DD 

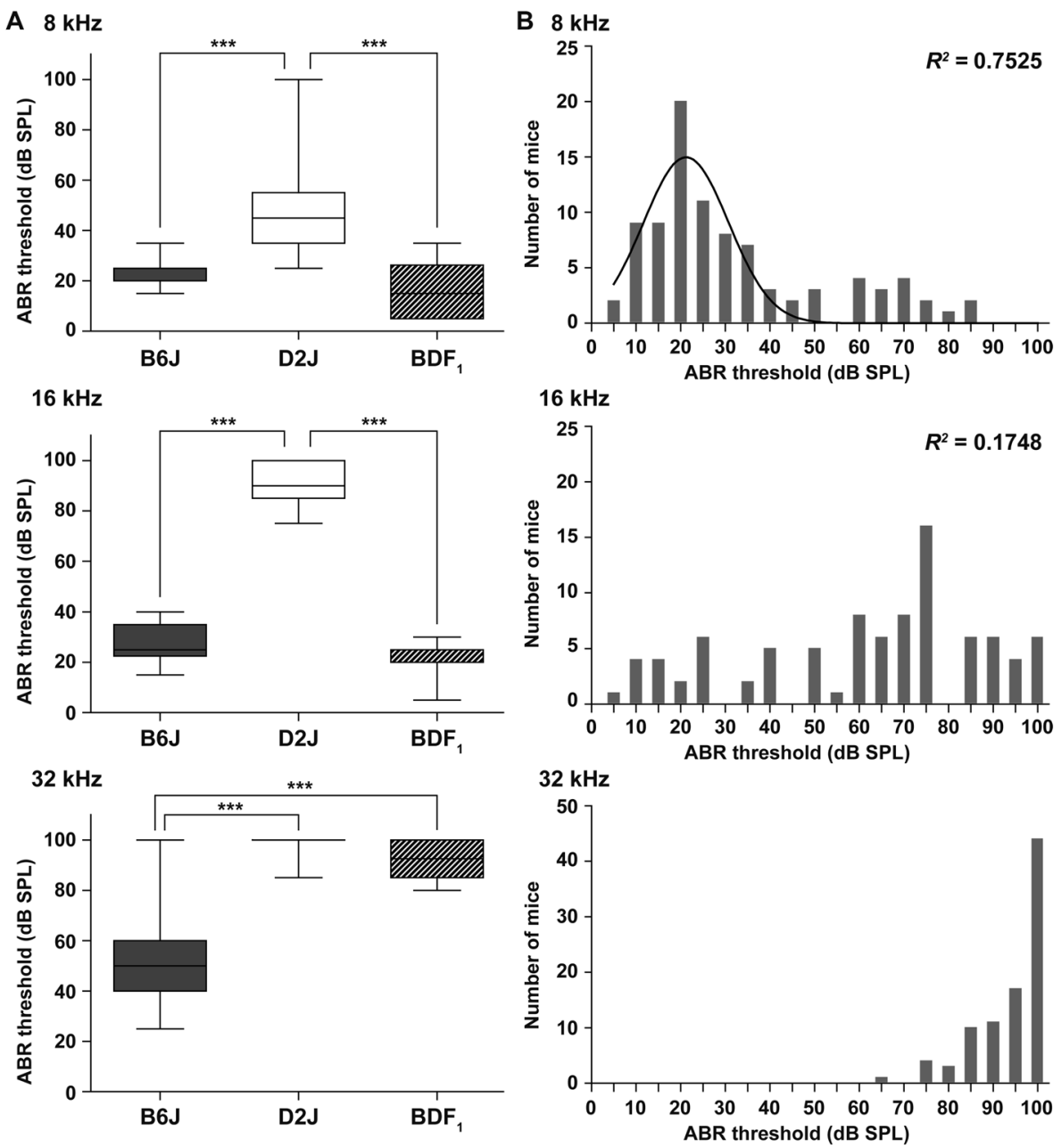

Fig. 3. Distributions of $A B R$ thresholds in $B 6 J, D 2 J, B D F_{1}$, and $\left(B D F_{1} \times D 2 J\right) N_{2}$ mice. (A) Distributions of ABR threshold measurements for 8-, 16-, and 32-kHz stimuli in B6J, D2J, and $\mathrm{BDF}_{1}$ mice at 3 months of age. The lines within boxes and error bars indicate the median and max/min thresholds, respectively. ${ }^{* * *} P<0.001$. (B) Distributions of ABR thresholds for 8-, 16-, and 32-kHz stimuli among the $\left(\mathrm{BDF}_{1} \times \mathrm{D} 2 \mathrm{~J}\right) \mathrm{N}_{2}$ mice. The best-fit curves for a Gaussian distribution are shown in black. The regression coefficient for the curve is given as $R^{2}$ calculated by the D'Agostino and Pearson tests.

homozygous genotype for the D2J allele at this locus (Fig. 5). Although some $\mathrm{N}_{2}$ mice with the DB heterozygous genotype at the Fscn $2^{\text {ahls }}$ locus developed hearing loss, the ABR thresholds from the DD and DB genotypes were significantly different (mean difference: $31.5 \mathrm{~dB}$ SPL, $P<0.001$, Fig. 5). Second, we analyzed the association between hearing loss and genotypes of D5Mit233, which showed the highest peak LOD on chromosome 5 in the QTL linkage analysis (Fig. 4 and Table 1). The mean difference between the DD and DB genotypes at this locus was $21.9 \mathrm{~dB}$ SPL. The difference was smaller than that of the Fscn $2^{\text {ahl }}$ locus, but it showed a significant difference (Fig. 5). Third, we investigated the indi- vidual effects of the genotypes of QTL and the interaction between the D2J alleles at both D11Mit103 and D5Mit233. The mean thresholds of individuals with hearing loss were decreased with the DB heterozygous genotype at both D11Mit103 and D5Mit233 compared with the DB heterozygous genotype at D11Mit103 only (Fig. 5). Moreover, the threshold in $\mathrm{N}_{2}$ mice with the DD genotype at D5Mit 233 was significantly higher than that of the $\mathrm{N}_{2}$ mice with the double DB heterozygous genotype at both D11Mit103 and D5Mit233, even if the genotype was DB heterozygous at D11Mit103 (Fig. 5). Thus, these results suggest that the DD homozygous allele at D5Mit233 contributed to the hearing loss at 


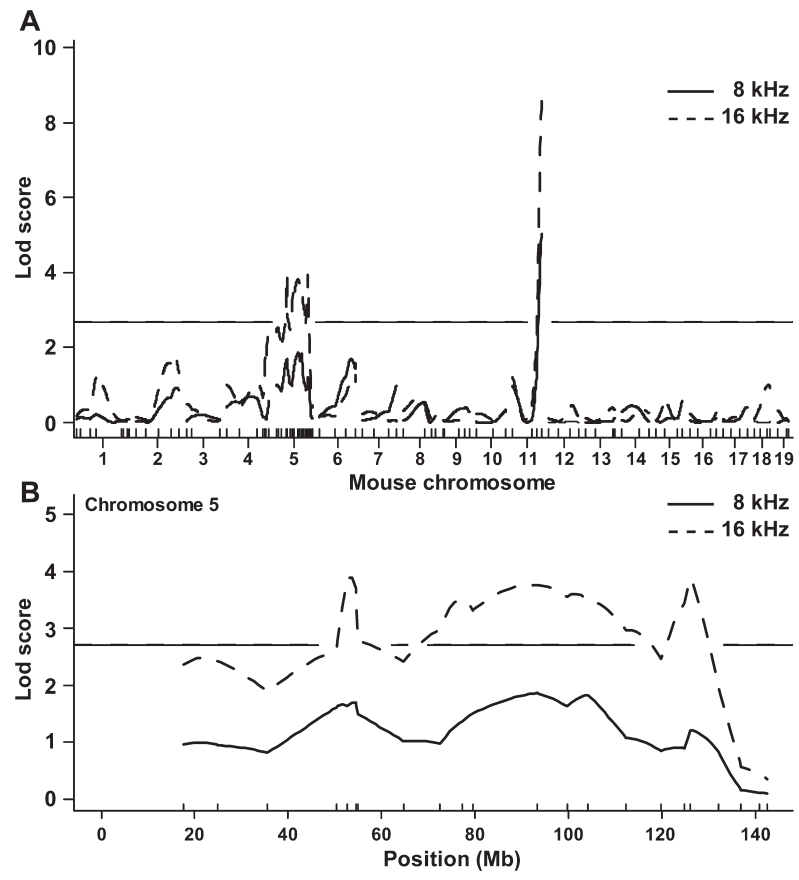

Fig. 4. Genome linkage analysis for early-onset hearing loss in D2J mice. (A) Genome-wide interval mapping for susceptibility genes associated with early-onset hearing loss for 8- (solid curve) and $16-\mathrm{kHz}$ (dotted curve) stimuli of the $\left(\mathrm{BDF}_{1} \times \mathrm{D} 2 \mathrm{~J}\right) \mathrm{N}_{2}$ mice. Chromosome numbers and marker positions (vertical bars) are given below the linkage map. The horizontal lines indicate significant LOD thresholds at $8($ solid, $\mathrm{LOD}=2.69)$ and $16($ dotted, $\mathrm{LOD}=2.71)$ $\mathrm{kHz}$, respectively. (B) Magnified view of the significant QTLs at chromosome 5.

$16 \mathrm{kHz}$ in $\mathrm{N}_{2}$ mice but that the effect of the DD homozygous allele at the Fscn $2^{\text {ahl }}$ locus was significant and was not affected by the genotypes at D5Mit233 (Fig. 5). Additionally, a similar effect was exerted by DD homozygous alleles in the other QTLs on chromosome 5 (Supplementary Fig. 1).

Most $\mathrm{N}_{2}$ mice with the DD homozygous genotypes at both D11Mit103 and D5Mit233 exhibited elevated ABR thresholds, and the mean threshold was identical to that of the DD homozygous genotype at D11Mit103 only (Fig. 5).

\section{Analyses of candidate genes on chromosome 5}

There are many genes related to hearing loss that function on chromosome 5 in mice [The Jackson Laboratory, Hereditary Hearing Impairment in Mice: http://hearingimpairment.jax.org/]. Because D2J mice showed degeneration of stereocilia in inner ear hair cells and because more severe degradation of stereocilia in the
Table 1. Detected susceptibly QTLs for early-onset AHL in $\left(\mathrm{BDF}_{1} \times \mathrm{D} 2 \mathrm{~J}\right) \mathrm{N}_{2}$ mice

\begin{tabular}{cclcc}
\hline $\begin{array}{c}\text { Frequency } \\
(\mathrm{kHz})\end{array}$ & Chr* & Marker name & $\begin{array}{c}\text { Ensembl } \\
\text { position (bp) }\end{array}$ & LOD score \\
\hline 8 & 11 & D11Mit203 & 116363361 & 4.95 \\
& 11 & D11Mit103 & 117167319 & 5.02 \\
16 & 5 & D5Mit233 & 52697226 & 3.91 \\
& 5 & D5Mit300 & 54486435 & 3.71 \\
& 5 & D5Mit255 & 54954339 & 2.80 \\
& 5 & D5Mit336 & 72488531 & 3.00 \\
& 5 & D5Mit113 & 77255215 & 3.52 \\
& 5 & D5Mit309 & 79502721 & 3.34 \\
& 5 & D5Mit7 & 93297205 & 3.78 \\
& 5 & D5Mit155 & 99690609 & 3.58 \\
& 5 & D5Mit10 & 104239005 & 3.50 \\
& 5 & D5Mit24 & 112317683 & 2.98 \\
& 5 & D5Mit95 & 124829235 & 3.46 \\
& 5 & D5Mit214 & 126090176 & 3.89 \\
& 11 & D11Mit203 & 116363361 & 8.35 \\
& 11 & D11Mit103 & 117167319 & 8.84 \\
\hline
\end{tabular}

*Chromosome.

basal turn is consistent with the initial onset of highfrequency hearing loss [29, 31], we screened genes on chromosome 5 with known relationships with the development and maintenance of stereocilia as candidates that could be responsible for hearing loss in D2J mice. We selected six genes-Ucn, Grxcr1, P2rx2, Sun1, Fscn1, and $A c t b$ - as candidates, and their expressions were observed in stereocilia $[1,11,27,28,35,36]$. Although the LOD scores were extremely low in the immediate vicinity of markers with Sun 1, Fscn1, and Actb (Fig. 6A), we performed resequence analysis of the coding region corresponding to the published sequences of their genes on cDNA and/or genomic DNA from D2J and B6J mice. However, resequencing of the coding regions of their genes did not show any sequence variation in either strain. Next, we carried out qRT-PCR analysis to validate the differences in gene expression in their genes using RNA isolated from the cochleae of $\mathrm{D} 2 \mathrm{~J}$ and $\mathrm{B} 6 \mathrm{~J}$ mice at 3 weeks of age because it is possible that mutations in the cis-acting elements of their genes affect gene expression. We performed qRT-PCR analyses in five genes because the bands of $U c n$ were not detected via RT-PCR analysis using RNAs isolated from the cochleae of both mice. Four of these transcripts-Grxcr1, P2rx2, Sun1, and $A c t b$ - did not exhibit significant expression changes between the D2J and B6J mice, but P2rx 2 was upregulated by $\sim 1.5$-fold at the mean expression level in D2J mice (Fig. 6B). Although the significant downregulation of $\sim 2.0$-fold in D2J mice was only detected in 


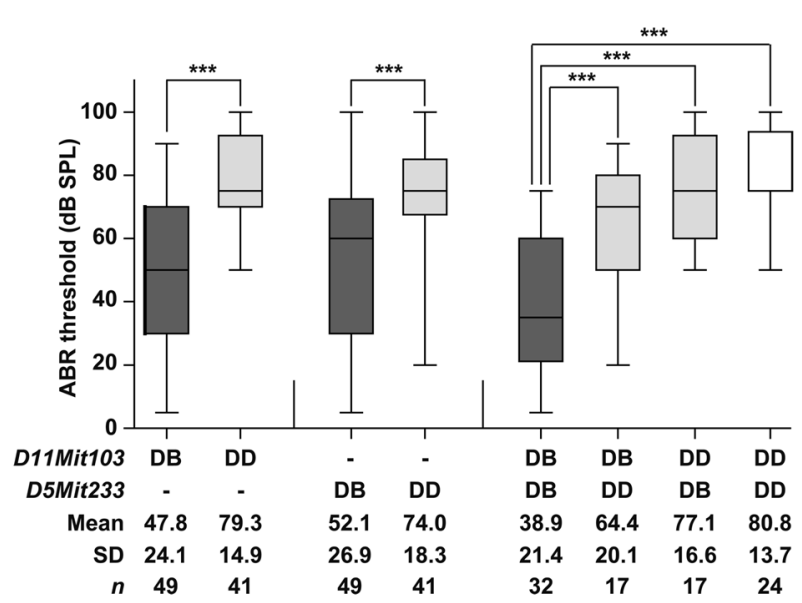

Fig. 5. Effects of the Fscn $2^{\text {ahl }}$ locus and a susceptibility locus on chromosome 5 on $\mathrm{ABR}$ thresholds at $16 \mathrm{kHz}$ in $\left(\mathrm{BDF}_{1} \times\right.$ D2J) $\mathrm{N}_{2}$ mice. The lines within boxes and error bars indicate the median and $\mathrm{max} / \mathrm{min}$ thresholds, respectively. The Fscn $2^{\text {ahls }}$ locus and a susceptibility locus on chromosome 5 were genotyped with D11Mit103 and D5Mit233, respectively. $* * * P<0.001$

Fscn1, a member of the Fascin family, in addition to Fscn2 [9] (Fig. 6B), we found that the LOD scores of the mapped position were extremely low (Fig. 6A).

\section{Discussion}

The D2J strain is a well-known mouse model of earlyonset AHL. In this study, we demonstrated that hearing loss increased to mid frequencies from ultrasonic frequencies according to the in ABR thresholds (Figs. 1 and 2; Supplementary Table 4). Previous studies have reported that early-onset AHL in D2J mice is controlled by the QTLs Cdh23 $3^{\text {ahl }}$ and Fscn2 $2^{\text {ahls }}$ [15]. We also confirmed the significant effect of Fscn $2^{\text {ahls }}$ on chromosome 11 for hearing loss with 8- and 16-kHz stimuli by QTL linkage analysis using $\left(\mathrm{BDF}_{1} \times \mathrm{D} 2 \mathrm{~J}\right) \mathrm{N}_{2}$ mice (Fig. 4 and Table 1). Using QTL analysis, we also found significant QTLs that contributed to hearing loss with only $16-\mathrm{kHz}$ stimuli on chromosome 5 . These QTLs were primarily detected as two comparatively sharp curves at peak LOD scores of the markers D5Mit233 (52.7 Mb) and D5Mit214 $(126.1 \mathrm{Mb})$ and a gently sloping curve at peak LOD scores of the marker D5Mit7 $(93.3 \mathrm{Mb})$. Among the QTLs, a QTL in the distal region (119.9-137.0 Mb) on chromosome 5 was also detected as suggested by previous studies on early-onset hearing loss with $16-\mathrm{kHz}$ stimuli in BXD recombinant inbred strains [15, 25]. Moreover, the individual effect of each QTL on chromo-
A Mouse chromosome 5

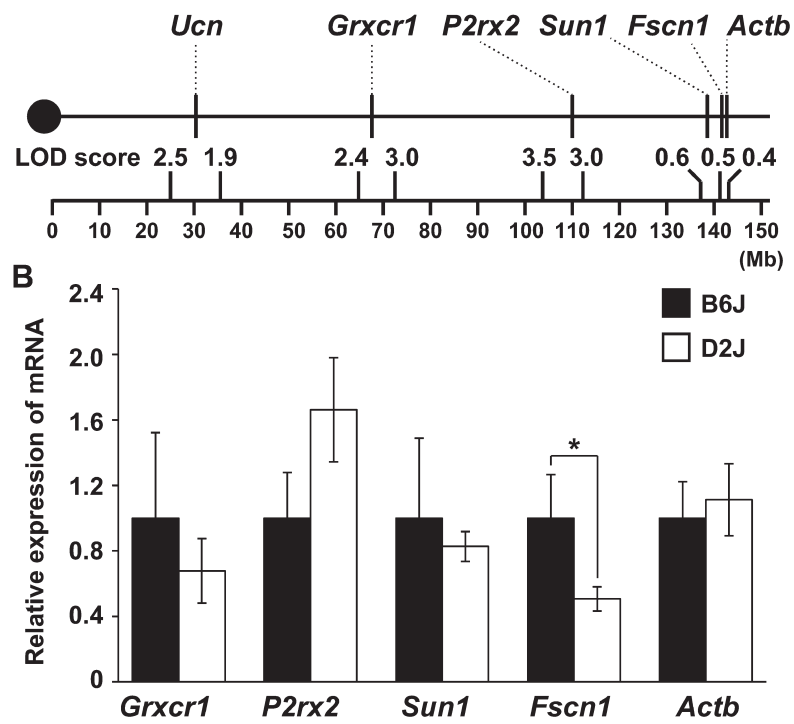

Fig. 6. Expression analysis of five selected candidate genes associated with the degeneration of stereocilia of the inner ear hair cells on chromosome 5. (A) The chromosomal locations of five candidate genes, Grxcr1, P2rx2, Sun1, Fscn1, and Actb, for the susceptibility to early-onset PHL in D2J mice. The LOD scores ( $16 \mathrm{kHz}$ ) of markers in the vicinity of their candidate genes are indicated. (B) The relative levels of mRNA in the cochlea of B6J (black bars) and D2J (white bars) mice at 3 weeks of age. mRNA expression was detected using real-time quantitative RTPCR analysis. ${ }^{*} P<0.05$.

some 5 was observed on early-onset hearing loss with 16-kHz stimuli (Fig. 5 and Supplementary Fig. 1), although we could not distinguish whether the QTLs effected an additive or nonadditive influence on early-onset hearing loss in D2J mice because the recombinants in the QTL regions on chromosome 5 of the $\mathrm{N}_{2}$ mice were insufficient to analyze the interactions among the QTLs.

The auditory systems of the mammals that perceive sounds in air are organized based on the separation of complex sounds into component frequencies [20]. This process begins at the level of the auditory sensory epithelium, where specific frequencies are distributed along the tonotopic axis of the mammalian cochlea such as the apex, middle, and base areas of the cochlea that correspond to the detection of sounds at low, mid, high, and ultrasonic frequencies, respectively [20, 24]. QTLs contributing to frequency-specific hearing loss have been reported in mice $[17,18]$. D2J mice represent a typical model for frequency-specific hearing loss according to the contributions of different QTLs. Nagtegaal et al. [25] 
suggested that $C d h 23^{a h l}$ and $F s c n 2^{a h l s}$ alleles make a large contribution to early-onset high-frequency hearing loss in D2J mice. The study also suggested that the ahl9 locus on chromosome 18 affects early-onset hearing loss with only low-frequency $(4 \mathrm{kHz})$ stimuli in D2J mice. In this study, we indicated that the QTLs on chromosome 5 affect early-onset hearing loss with only high-frequency (16 kHz) stimuli (Fig. 4), although their effect can be demonstrated by phenotypic analyses for hearing in congenic mice in QTL regions on chromosome 5. In addition, we demonstrated that the contribution of Fscn $2^{\text {ahl }}$ towards early-onset hearing loss with an ultrasonic frequency stimulus of $32 \mathrm{kHz}$ is extremely low. This was because most $F s c n 2^{a h l 8 /+}$ heterozygotes from $\mathrm{BDF}_{1}$ and $\left(\mathrm{BDF}_{1} \times \mathrm{D} 2 \mathrm{~J}\right) \mathrm{N}_{2}$ mice showed profound hearing loss at 3 months of age (Fig. 3). Cdh $23^{\text {ahl }}$ is believed to play a major role in this process, as all mice belonging to the $\mathrm{BDF}_{1}$ and $\left(\mathrm{BDF}_{1} \times \mathrm{D} 2 \mathrm{~J}\right) \mathrm{N}_{2}$ groups displayed the homozygous $C d h 23^{\text {ahl }}$ allele. However, the ABR thresholds of $\mathrm{BDF}_{1}$ and $\left(\mathrm{BDF}_{1} \times \mathrm{D} 2 \mathrm{~J}\right) \mathrm{N}_{2}$ mice were similar to that observed in $\mathrm{D} 2 \mathrm{~J}$ mice and extremely high compared with that of B6J mice (Fig. 3). Therefore, we speculated that another dominant modifier gene(s) may have resulted in early-onset hearing loss at ultrasonic frequency. Altogether, these data indicated that the hearing loss of D2J mice is controlled by frequency-specific functional QTLs.

Many genes and several mutations in different genes are contained in the QTLs on chromosome 5 [Wellcome Trust Sanger Institute, Mouse Genomes Project: http:// www.sanger.ac.uk/resources/mouse/genomes/]. We performed mutation screening and expression analysis for six of these genes, which are expressed in the stereocilia of cochlear hair cells $[1,11,27,28,35,36]$. Of these genes, Fscn1 is a functional strong candidate gene because it is a paralogous gene of Fscn 2 and binds to crosslinks of actin filaments like Fscn2 [9]. Actb is also a functional candidate. Actb-flox Foxg1-cre mice show age-related degeneration of stereocilia similar to the short stereocilia phenotypes in D2J mice [28]. Although sequence variations were not detectable in the coding sequences of either gene, we found that expression of the Fscn 1 transcript was significantly downregulated in the cochlea in D2J mice (Fig. 6B). However, the LOD scores (0.4-0.5) of the immediate vicinity markers with Fscn1 were extremely low (Fig. 6A). Fscn1 is abundant in stereocilia bundles [32]; therefore, we speculated that the reduction in Fscn 1 may be caused by structural de- fects in the stereocilia of D2J mice. Additionally, there were no sequence variations and significant expression changes in the other functional candidate genes of the QTL regions on chromosome 5.

In mice, the ahl2 locus is mapped to chromosome 5, with a peak LOD score of 5.5 for D5Mit309 $(79.5 \mathrm{Mb})$, and is associated with early-onset AHL in NOD/LtJ mice [14]. The LOD score of D5Mit309 is 3.34 for hearing loss with 16-kHz stimuli by QTL linkage analysis using $\left(\mathrm{BDF}_{1} \times \mathrm{D} 2 \mathrm{~J}\right) \mathrm{N}_{2}$ mice (Table 1), and the ahl2 position is included in the interval $(64.6-119.9 \mathrm{Mb})$ of a QTL (Fig. 4B). Therefore, the QTL may be allelic to the recessive deafness gene at the ahl2 locus.

In humans, several loci associated with hearing loss are mapped to the syntenic region with mouse chromosome 5 [Hereditary Hearing Loss Homepage: http:// hereditaryhearingloss.org/]. Within their loci, possible mutations in a human gene orthologous to the QTLs include two loci, DFNB40 and DFNB55, for recessive non-syndromic early-onset AHL. The DFNB40 and DFNB55 loci are included in the interval of a QTL (64.6-119.9 Mb) for early-onset AHL in D2J mice $[4,12]$. Moreover, the QTL overlaps with the DFNA27 locus for dominant early-onset AHL [30]. Although the causative mutations of the loci remain unknown, D2J mice are likely to provide useful information regarding cloned mutations from their loci if causative mutations for the QTLs associated with early-onset AHL in D2J mice can be identified in future genetic analyses.

\section{Acknowledgments}

We thank Erika Samusawa for technical assistance. This work was financially supported by JSPS KAKENHI (Grants-in-Aid for Scientific Research B, Grant Numbers 20300147 and 23300160, Y. Kikkawa; Grantin-Aid for JSPS Fellows, Grant Number 13J05376, S. Suzuki).

\section{References}

1. Avenarius, M.R., Saylor, K.W., Lundeberg, M.R., Wilmarth, P.A., Shin, J.B., Spinelli, K.J., Pagana, J.M., Andrade, L., Kachar, B., Choi, D., David, L.L., and Barr-Gillespie, P.G. 2014. Correlation of actin crosslinker and capper expression levels with stereocilia growth phases. Mol. Cell. Proteomics 13: 606-620. [Medline] [CrossRef]

2. Broman, K.W. and Sen, Ś. 2009. A Guide to QTL Mapping with R/qtl, Springer, New York.

3. Casellas, J. 2011. Inbred mouse strains and genetic stability: 
a review. Animal 5: 1-7. [Medline] [CrossRef]

4. Delmaghani, S., Aghaie, A., Compain-Nouaille, S., Ataie, A., Lemainque, A., Zeinali, S., Lathrop, M., Weil, D., and Petit, C. 2003. DFNB40, a recessive form of sensorineural hearing loss, maps to chromosome 22q11.21-12.1. Eur. J. Hum. Genet. 11: 816-818. [Medline] [CrossRef]

5. Dickson, S.P., Wang, K., Krantz, I., Hakonarson, H., and Goldstein, D.B. 2010. Rare variants create synthetic genome-wide associations. PLoS Biol. 8: e1000294. [Medline] [CrossRef]

6. Fransen, E., Lemkens, N., Van Laer, L., and Van Camp, G. 2003. Age-related hearing impairment (ARHI): environmental risk factors and genetic prospects. Exp. Gerontol. 38: 353-359. [Medline] [CrossRef]

7. Friedman, R.A., Van Laer, L., Huentelman, M.J., Sheth, S.S., Van Eyken, E., Corneveaux, J.J., Tembe, W.D., Halperin, R.F., Thorburn, A.Q., Thys, S., Bonneux, S., Fransen, E., Huyghe, J., Pyykkö, I., Cremers, C.W., Kremer, H., Dhooge, I., Stephens, D., Orzan, E., Pfister, M., Bille, M., Parving, A., Sorri, M., Van de Heyning, P.H., Makmura, L., Ohmen, J.D., Linthicum, F.H. Jr., Fayad, J.N., Pearson, J.V., Craig, D.W., Stephan, D.A., and Van Camp, G. 2009. GRM7 variants confer susceptibility to age-related hearing impairment. Hum. Mol. Genet. 18: 785-796. [Medline] [CrossRef]

8. Girotto, G., Vuckovic, D., Buniello, A., Lorente-Cánovas, B., Lewis, M., Gasparini, P., and Steel, K.P. 2014. Expression and replication studies to identify new candidate genes involved in normal hearing function. PLOS ONE 9: e85352. [Medline] [CrossRef]

9. Hashimoto, Y., Kim, D.J., and Adams, J.C. 2011. The roles of fascins in health and disease. J. Pathol. 224: 289-300. [Medline] [CrossRef]

10. Henry, K.R. and Chole, R.A. 1980. Genotypic differences in behavioral, physiological and anatomical expressions of age-related hearing loss in the laboratory mouse. Audiology 19: 369-383. [Medline] [CrossRef]

11. Horn, H.F., Brownstein, Z., Lenz, D.R., Shivatzki, S., Dror, A.A., Dagan-Rosenfeld, O., Friedman, L.M., Roux, K.J., Kozlov, S., Jeang, K.T., Frydman, M., Burke, B., Stewart, C.L., and Avraham, K.B. 2013. The LINC complex is essential for hearing. J. Clin. Invest. 123: 740-750. [Medline]

12. Irshad, S., Santos, R.L., Muhammad, D., Lee, K., McArthur, N., Haque, S., Ahmad, W., and Leal, S.M. 2005. Localization of a novel autosomal recessive non-syndromic hearing impairment locus DFNB55 to chromosome 4q12-q13.2. Clin. Genet. 68: 262-267. [Medline] [CrossRef]

13. Johnson, K.R., Zheng, Q.Y., and Erway, L.C. 2000. A major gene affecting age-related hearing loss is common to at least ten inbred strains of mice. Genomics 70: 171-180. [Medline] [CrossRef]

14. Johnson, K.R. and Zheng, Q.Y. 2002. Ahl2, a second locus affecting age-related hearing loss in mice. Genomics 80 : 461-464. [Medline] [CrossRef]

15. Johnson, K.R., Longo-Guess, C., Gagnon, L.H., Yu, H., and Zheng, Q.Y. 2008. A locus on distal chromosome 11 (ahl8) and its interaction with $C d h 23$ ahl underlie the early onset, age-related hearing loss of DBA/2J mice. Genomics 92: 219-225. [Medline] [CrossRef]
16. Keane, T.M., Goodstadt, L., Danecek, P., White, M.A., Wong, K., Yalcin, B., Heger, A., Agam, A., Slater, G., Goodson, M., Furlotte, N.A., Eskin, E., Nellåker, C., Whitley, H., Cleak, J., Janowitz, D., Hernandez-Pliego, P., Edwards, A., Belgard, T.G., Oliver, P.L., McIntyre, R.E., Bhomra, A., Nicod, J., Gan, X., Yuan, W., van der Weyden, L., Steward, C.A., Bala, S., Stalker, J., Mott, R., Durbin, R., Jackson, I.J., Czechanski, A., Guerra-Assunção, J.A., Donahue, L.R., Reinholdt, L.G., Payseur, B.A., Ponting, C.P., Birney, E., Flint, J., and Adams, D.J. 2011. Mouse genomic variation and its effect on phenotypes and gene regulation. Nature 477: 289 294. [Medline] [CrossRef]

17. Keller, J.M., Neely, H.R., Latoche, J.R., and Noben-Trauth, K. 2011. High-frequency sensorineural hearing loss and its underlying genetics (Hfhll and Hfhl2) in NIH Swiss mice. J. Assoc. Res. Otolaryngol. 12: 617-631. [Medline] [CrossRef]

18. Keller, J.M. and Noben-Trauth, K. 2012. Genome-wide linkage analyses identify $H f h l l$ and $H f h l 3$ with frequency-specific effects on the hearing spectrum of NIH Swiss mice. BMC Genet. 13: 32. [Medline] [CrossRef]

19. Kikkawa, Y., Seki, Y., Okumura, K., Ohshiba, Y., Miyasaka, Y., Suzuki, S., Ozaki, M., Matsuoka, K., Noguchi, Y., and Yonekawa, H. 2012. Advantages of a mouse model for human hearing impairment. Exp. Anim. 61: 85-98. [Medline] [CrossRef]

20. Mann, Z.F. and Kelley, M.W. 2011. Development of tonotopy in the auditory periphery. Hear. Res. 276: 2-15. [Medline] [CrossRef]

21. Mills, J.H. and Going, J.A. 1982. Review of environmental factors affecting hearing. Environ. Health Perspect. 44: 119-127. [Medline] [CrossRef]

22. Miyasaka, Y., Suzuki, S., Ohshiba, Y., Watanabe, K., Sagara, Y., Yasuda, S.P., Matsuoka, K., Shitara, H., Yonekawa, H., Kominami, R., and Kikkawa, Y. 2013. Compound heterozygosity of the functionally null $C d h 23^{v-n g t}$ and hypomorphic $C d h 23^{\text {ahl }}$ alleles leads to early-onset progressive hearing loss in mice. Exp. Anim. 62: 333-346. [Medline] [CrossRef]

23. Morton, C.C. and Nance, W.E. 2006. Newborn hearing screening - a silent revolution. N. Engl. J. Med. 354: 21512164. [Medline] [CrossRef]

24. Müller, M., von Hünerbein, K., Hoidis, S., and Smolders, J.W. 2005. A physiological place-frequency map of the cochlea in the CBA/J mouse. Hear. Res. 202: 63-73. [Medline] [CrossRef]

25. Nagtegaal, A.P., Spijker, S., Crins, T.T., Neuro-Bsik Mouse Phenomics Consortium, and Borst, J.G. 2012. A novel QTL underlying early-onset, low-frequency hearing loss in BXD recombinant inbred strains. Genes Brain Behav. 11: 911920. [Medline]

26. Noben-Trauth, K., Zheng, Q.Y., and Johnson, K.R. 2003. Association of cadherin 23 with polygenic inheritance and genetic modification of sensorineural hearing loss. Nat. Genet. 35: 21-23. [Medline] [CrossRef]

27. Odeh, H., Hunker, K.L., Belyantseva, I.A., Azaiez, H., Avenarius, M.R., Zheng, L., Peters, L.M., Gagnon, L.H., Hagiwara, N., Skynner, M.J., Brilliant, M.H., Allen, N.D., Riazuddin, S., Johnson, K.R., Raphael, Y., Najmabadi, H., 
Friedman, T.B., Bartles, J.R., Smith, R.J., and Kohrman, D.C. 2010. Mutations in Grxcrl are the basis for inner ear dysfunction in the pirouette mouse. Am. J. Hum. Genet. 86: 148-160. [Medline] [CrossRef]

28. Perrin, B.J., Sonnemann, K.J., and Ervasti, J.M. 2010. $\beta$-actin and $\gamma$-actin are each dispensable for auditory hair cell development but required for Stereocilia maintenance. PLoS Genet. 6: e1001158. [Medline] [CrossRef]

29. Perrin, B.J., Strandjord, D.M., Narayanan, P., Henderson, D.M., Johnson, K.R., and Ervasti, J.M. 2013. $\beta$-Actin and fascin-2 cooperate to maintain stereocilia length. J. Neurosci. 33: 8114-8121. [Medline] [CrossRef]

30. Peters, L.M., Fridell, R.A., Boger, E.T., San Agustin, T.B., Madeo, A.C., Griffith, A.J., Friedman, T.B., and Morell, R.J. 2008. A locus for autosomal dominant progressive non-syndromic hearing loss, DFNA27, is on chromosome 4q12-13.1. Clin. Genet. 73: 367-372. [Medline] [CrossRef]

31. Shin, J.B., Longo-Guess, C.M., Gagnon, L.H., Saylor, K.W., Dumont, R.A., Spinelli, K.J., Pagana, J.M., Wilmarth, P.A., David, L.L., Gillespie, P.G., and Johnson, K.R. 2010. The $\mathrm{R} 109 \mathrm{H}$ variant of fascin-2, a developmentally regulated actin crosslinker in hair-cell stereocilia, underlies early-onset hearing loss of DBA/2J mice. J. Neurosci. 30: 9683-9694. [Medline] [CrossRef]

32. Shin, J.B., Krey, J.F., Hassan, A., Metlagel, Z., Tauscher, A.N., Pagana, J.M., Sherman, N.E., Jeffery, E.D., Spinelli, K.J., Zhao, H., Wilmarth, P.A., Choi, D., David, L.L., Auer, M., and Barr-Gillespie, P.G. 2013. Molecular architecture of the chick vestibular hair bundle. Nat. Neurosci. 16: 365-374. [Medline] [CrossRef]

33. Takada, T., Ebata, T., Noguchi, H., Keane, T.M., Adams, D.J., Narita, T., Shin-I, T., Fujisawa, H., Toyoda, A., Abe, K., Obata, Y., Sakaki, Y., Moriwaki, K., Fujiyama, A., Kohara,
Y., and Shiroishi, T. 2013. The ancestor of extant Japanese fancy mice contributed to the mosaic genomes of classical inbred strains. Genome Res. 23: 1329-1338. [Medline] [CrossRef]

34. Van Laer, L., Huyghe, J.R., Hannula, S., Van Eyken, E., Stephan, D.A., Mäki-Torkko, E., Aikio, P., Fransen, E., Lysholm-Bernacchi, A., Sorri, M., Huentelman, M.J., and Van Camp, G. 2010. A genome-wide association study for age-related hearing impairment in the Saami. Eur. J. Hum. Genet. 18: 685-693. [Medline] [CrossRef]

35. Vetter, D.E., Li, C., Zhao, L., Contarino, A., Liberman, M.C., Smith, G.W., Marchuk, Y., Koob, G.F., Heinemann, S.F., Vale, W., and Lee, K.F. 2002. Urocortin-deficient mice show hearing impairment and increased anxiety-like behavior. Nat. Genet. 31: 363-369. [Medline]

36. Yan, D., Zhu, Y., Walsh, T., Xie, D., Yuan, H., Sirmaci, A., Fujikawa, T., Wong, A.C., Loh, T.L., Du, L., Grati, M., Vlajkovic, S.M., Blanton, S., Ryan, A.F., Chen, Z.Y., Thorne, P.R., Kachar, B., Tekin, M., Zhao, H.B., Housley, G.D., King, M.C., and Liu, X.Z. 2013. Mutation of the ATP-gated $\mathrm{P} 2 \mathrm{X}_{2}$ receptor leads to progressive hearing loss and increased susceptibility to noise. Proc. Natl. Acad. Sci. USA 110: 2228-2233. [Medline] [CrossRef]

37. Yokoyama, J.S., Lam, E.T., Ruhe, A.L., Erdman, C.A., Robertson, K.R., Webb, A.A., Williams, D.C., Chang, M.L., Hytönen, M.K., Lohi, H., Hamilton, S.P., and Neff, M.W. 2012. Variation in genes related to cochlear biology is strongly associated with adult-onset deafness in border collies. PLoS Genet. 8: e1002898. [Medline] [CrossRef]

38. Zheng, Q.Y., Johnson, K.R., and Erway, L.C. 1999. Assessment of hearing in 80 inbred strains of mice by ABR threshold analyses. Hear. Res. 130: 94-107. [Medline] [CrossRef] 